Research Paper

\title{
Analyzing Consumer Responses to Humane-oriented CSR Advertising Appeals in an Age of Corporate Social Responsibility: The Case of Japan vs. the U.S.
}

Barbara Mueller

Corresponding author: muelle1@mail.sdsu.edu

San Diego State University, USA

SANDRA DIEHL

Klagenfurt University, Austria

RAlF Terlutter

Klagenfurt University, Austria

MorikazU Hirose

Tokyo Fuji University, Japan

\section{Abstract}

This investigation seeks to explore the role of Humane Orientation (HO) - one of the cultural dimensions outlined in the GLOBE framework - in responses to advertisements containing corporate social responsibility (CSR) messages among consumers in Japan and the U.S. The academic literature examining Japanese consumer responses to CSR messages in marketing communications is particularly sparse. The model of cross-cultural consumer responses to HO appeals in advertising developed by Diehl, Terlutter, and Mueller (2015) is tested using structural equation modelling in the two countries. A non-student sample of 251 Japanese was compared with data previously collected in the U.S. Results revealed the model to be valid for Japan as well. The higher the perceived degree of HO in an $\mathrm{ad}$, the more positive was the evaluation of the ad, and the more likely subjects were to evaluate the advertiser as being socially responsible. These two variables positively influenced attitude toward the product and subsequent purchase intention. Individual HO values were lower in Japan than in the U.S., and HO paths were found to be lower as well. In summary, despite the lower but still significant influence of HO on ad effects in Japan, results suggest that international advertisers may pursue a standardized campaign in multiple markets when incorporating humane-oriented ad appeals.

Keywords:Corporate Social Responsibility, GLOBE Dimensions, Humane Orientation, Japan 


\section{Introduction}

Recent industry-sponsored polls, including the 2017 Edelman Earned Brand study, the 2015 Cone Communications/Ebiquity Global Corporate Social Responsibility study, and the 2014 Nielsen Doing Well by Doing Good study, suggest that consumers around the world are demanding a higher level of responsibility from companies in dealing with societal issues - and consumers are using their spending-power and loyalty to push these issues. In markets with similar levels of concern, the potential for standardized messages employing Corporate Social Responsibility (CSR) appeals exists. There appears to be ample evidence that standardized advertising is more feasible than ever before, and the benefits of a common marketing and, in particular, advertising strategy, are manifold (Mueller and Taylor, 2013). However, survey findings also revealed important nuances by country - with consumers in some markets expressing significantly greater concern over CSR - and their willingness to act on these concerns - than those in others. This suggests that CSR strategies may well be perceived and evaluated differently in local markets, thereby requiring a customized approach to advertising messages. Therefore, it is essential that corporations have an in-depth understanding of what will motivate consumers with regards to CSR in each culture (IB Times, 2011). An explanation for the variation in consumer responses to the issue of CSR may be differences in their level of humane orientation in each market. Humane Orientation is one of the nine cultural dimensions outlined in the Global Leadership and Organizational Behavior Effectiveness Research (GLOBE) framework (House et al. 2004) and is closely related to CSR. Farooq, Farooq, and Jasimuddin (2014) distinguish between philanthropic, customer-, employee- and environmentoriented domains in CSR and humane orientation is closely related to the philanthropic domain. Humane orientation is the extent to which society encourages and rewards its members for being fair, altruistic, friendly, caring, and kind to others (House et al., 2004). This investigation seeks to explore the role of the cultural dimension of Humane Orientation (HO), in responses to advertisements containing humane-oriented CSR messages among consumers in Japan and the U.S. The rationale for the country selection is as follows: Japan and the U.S. represent two of the world's top three economies and while their Globe scores for humane orientation values and practices do not differ

significantly, they differ considerably in terms of their CSR history and consumers' perceptions of their responsibilities related to CSR, as will be outlined in the following. Thus, it is of interest to explore whether CSR appeals yield similar or different effects among consumers in both countries. The model of cross-cultural consumer responses to humane-oriented appeals in advertising developed by Diehl, Terlutter and Mueller (2015), which proved to be valid for the U.S. market, is tested in the Japanese market as well.

\section{Global Trends in Corporate Social Responsibility}

The recent Edelman Earned Brands Study (2017) reports that of 14,000 consumers surveyed in 14 countries, 51 percent believed that brands can do more to solve social ills than governments. Based on a survey of more than 9,700 consumers in nine of the largest countries in the world by GDP, Cone Communications found a firm's social actions play a significant role in forming consumers' impressions of companies. Global consumers state they have a more positive image (93 percent), are more likely to trust (90 percent) and are more loyal to (88 percent) companies that support social and environmental issues (Cone Communications/Ebiquity Global CSR Report, 2015). More important, consumer's impressions of corporations influence their behavior. Nielsen, polling 30,000 consumers in 60 countries found 52 percent of consumers made at least one purchase in the past six months from a socially responsible 
company, 55 percent are willing to pay extra for goods from companies committed to positive social and environmental impact, 49 percent volunteer and/or donate to organizations engaged in social and environmental programs, and 67 percent prefer to work for socially responsible firms (Nielsen Doing Well by Doing Good Report, 2014). While these surveys suggest that corporate social responsibility (CSR) as a marketing imperative has global consumer appeal, findings also revealed important nuances by country. It appears that consumers in some markets express significantly greater concern over CSR - and their willingness to act on these concerns - than those in others. Alongside the developing nations of Brazil and India, China is highest in terms of enthusiasm for company CSR efforts. In contrast, many Western European nations, North America, and Japan, rank below the global average score. This suggests that corporations must recognize that corporate responsibility strategies may well be perceived and evaluated differently in various markets.

Companies engage in a wide variety of CSR activities, among them corporate philanthropy and cause-related marketing (CRM), as well as socially responsible employment and manufacturing practices (Bhattacharya and Sen, 2004). Each of these activities can be communicated in a number of ways: annual reports, websites, product packaging, press releases and advertising. CSR appeals in marketing and advertising have dramatically increased in recent years, but despite this trend, research on the topic is still not highly developed (see Ettinger, Terlutter, Diehl and Mueller, 2017), and there is limited understanding of the variables and processes involved in consumer responses to CSR communication (Wang and Anderson, 2011). Moreover, there is a clear paucity of research on how CSR appeals are perceived and evaluated in different cultures (Matten and Mood, 2008), a research gap recognized by numerous investigators (Pomering and Dolnicar, 2009; and Yoon, Zeynep and Schwarz, 2006; Ettinger et al., 2017; and most recently, Taylor, 2018).

\section{Consumer Attitudes toward CSR in Japan and the U.S.}

Japan and the U.S. are among the top three economies in the world (World Economic Forum, 2017) making them of particular appeal to global marketers. Based on recent industry sponsored surveys, consumer attitudes toward CSR in the two countries appear - on the surface - seem to be rather similar (both countries ranking below the global average score), yet the two countries are culturally quite dissimilar and have very different histories with regard to CSR. Fukukawa and Teramoto (2009) argue that the development of the concept has "arguably been based on a predominantly Western-led discourse. The philosophical and ideological underpinning of CSR remain rooted in Anglo-American and European principles of liberal demographic rights, justice and social structures, (p. 134)." Matten and Moon (2004) suggest that the North American concept of CSR represents the original context of the phenomenon by emphasizing its philanthropic aspects, and that firms in the U.S. typically attach issues of social responsibility explicitly in their mission statements, policies and strategy. In contrast, CSR, narrowly defined, is a relative newcomer to Japan. Indeed, the year 2003 is often referred to in Japan as "CSR gannen" (the first year of CSR), (Fukukawa and Teramoto, 2009). But this should not suggest that the principles behind CSR are foreign to Japanese businesses - they are deeply embedded in Japanese culture and language. Japanese companies are considered members of society and hence responsible to it (DeMente, 2001). Firms are said to form the basis of society. Smith, Singal and Lamb (2008) report that the words "keizai (economy) and keiei (business) are not value-free but already contain a normative-ethical component namely 'governing the world in harmony' (kei), 'bringing about the wellbeing of people' (zai) and 'making ceaseless efforts to achieve (these purposes)' (ei)." Because corporations, their employees, and their customers are embedded in different cultural systems, they will likely embrace different attitudes 
toward CSR. A solid number of investigations exist which explore the perceptions and practices of the managers and employees of Japanese corporations with regards to CSR (Witt and Stahl, 2016; Witt and Redding, 2012; Mueller, Hattrup, Spiess and Lin-Hi, 2012; Fukukawa and Teramoto, 2009; Choi and Aguilera, 2009; and Fukukawa and Moon, 2004). However, academic studies on the Japanese consumer perspective are almost non-existent, at least in English-language publications.

The Edelman goodpurpose report (2012) asked, among other questions: "Who should be most responsible for addressing societal issues?" Responses included "government," "corporations," or "people like me." Fully 73 percent of Japanese survey participants indicated they felt the government should be primarily responsible, while only 10 percent indicated "people like me." In contrast, only 22 percent of Americans felt governments should take the lead, while 35 percent believed "people like me" should be the most responsible.

The Cone Communications/Ebiquity Global Study (2015) also provides deeper insights into Japanese and American consumer attitudes toward CSR. Their data suggests that CSR in Japan continues to rely predominantly on businesses to make social and environmental changes. While Japanese consumers maintain high expectations of corporations, they are less likely to see a personal role for themselves, thus confirming the results of the Edelman report. Most Japanese (85 percent vs. 91 percent global average) expect companies to do more than make a profit - they must also operate responsibly by addressing social and environmental issues. However, of the nine countries surveyed by Cone Communications, Japanese consumers stood out with the lowest levels of enthusiasm for direct participation in companies' CSR efforts. They were the least likely market to switch products to one associated with a cause (72 percent vs. 90 percent global average) or to proactively seek out responsible products when they shop (68 percent vs 84 percent global average). Japanese were the least likely to have purchased a responsible product in the past 12 months (43 percent vs. 63 percent global average). Americans also have high expectations for companies to do more than make a profit (87 percent). Additionally, Americans mirror the global average when considering a company's CSR commitments in making important decisions, including which companies they want doing business in their community (84 percent vs. 84 percent global average), where to shop ( 80 percent vs. 84 percent global average), and which products and services to recommend to others (78 percent vs. 82 percent global average). However, the data do reveal a reduction in American consumers reported purchase of products with social and environmental benefits (56 percent in 2015 vs. 72 percent in 2011). Academic literature examining Japanese consumer responses to CSR messages in marketing communications is particularly sparse. An extensive literature review revealed only two such investigations - both of which focused on CRM - a form of corporate social responsibility (Stanislawski, Sonobe and Ohira, 2014; and Cheron, Kohlbacher and Kusuma, 2012), thus indicating a relevant research gap. CRM typically involves partnerships between for-profit and non-profit organizations for mutual benefits. CRM is defined as the contribution to a designated cause by a firm, in which the specified contribution is conditional on "customers engaging in revenue-providing exchanges that satisfy organizational and individual objectives" (Varadarajan and Menon, 1988, p. 60). This partnership is communicated to customers through marketing campaigns, with the dual goal of raising awareness and funds for the non-profit while also increasing sales for the firm and building the brand's reputation as socially responsible. Stanislawski et al. (2014) examined the impact of CRM appeals on product packaging and found that the mere presence of a CRM message (whether vague or detailed) resulted in significantly more positive attitudes and higher purchase intention among Japanese consumers. However, providing greater detail about the CSR initiative did not result in significant differences. Cheron, Kohlbacher and Kasuma (2012) also examined Japanese consumer responses toward cause related marketing. They found that a high brand-cause fit elicited more positive attitudes toward the CRM program than did the duration of the campaign. Since both CSR initiatives and consumer 
responses toward CSR advertising differ between cultures in complex ways, it is of value to understand how cultural values influence consumer behavior in a CSR context.

\section{Theoretical Background}

The role of culture in international advertising has been discussed for decades and today is recognized as an increasingly important topic for research (Ford et al. 2011). Culture can be viewed as a set of all-permeating values infused in the cultural group in focus through family, friends, social groups, church and daily media (Okazaki and Mueller, 2007). An important area of cross-cultural advertising research identifies sets of cultural values useful in describing cultures. In past decades, a number of frameworks have emerged which have outlined cultural dimensions that attempt to explain a significant portion of country-to-country variance. Among them are Kluckhohn and Strodbeck's dimensions (1960), Hall's dimensions (Hall, 1976), Hofstede's typology of cultural values (1980, 2001), Schwartz's cultural values (1992, 1994), Inglehart's World Values Survey (see http://www.worldvaluessurvey.org), and most recently, the GLOBE project (House et al., 2004). While Hofstede's classification has been the most widely adopted (de Mooij and Hofstede, 2010), others have been tested less frequently in cross-cultural investigations. In what follows, the Project GLOBE framework is briefly outlined. GLOBE provides data for 62 cultures, based on a survey of 17,300 middle managers in 951 organizations. In recognizing the work of a large number of cross-cultural researchers, the GLOBE framework provides a broader theoretical foundation for their cultural dimensions. Over 170 GLOBE researchers from different cultural backgrounds worked together on construct definition, construct conceptualization, and on measurement of the constructs. GLOBE outlines nine cultural dimensions:

(1) assertiveness, the degree to which individuals in societies are assertive, confrontational, aggressive, and straightforward;

(2) uncertainty avoidance, the extent to which members of a society strive to avoid uncertainty by relying on established social norms and practices;

(3) power distance, the degree to which members of a society expect and accept that power is distributed unequally;

(4) collectivism I (institutional collectivism), the degree to which societal institutional practices encourage and reward collective distribution of resources and collective action, as opposed to individual distribution and individual action;

(5) collectivism II (in-group collectivism), the extent to which members of a society express pride, loyalty, and cohesiveness in their groups, organizations or families;

(6) gender egalitarianism, the degree to which a society minimizes gender role differences;

(7) future orientation, the degree to which members of a society engage in future-oriented behaviors such as planning, investing, and delaying gratification;

(8) performance orientation, the degree to which a society encourages and regards group members for performance improvement and excellence;

(9) humane orientation, the extent to which society encourages and rewards its members for being fair, altruistic, friendly, caring, and kind to others (House et al., 2004).

In response to numerous calls for further application of the Project GLOBE framework (House et al. 2004; House et al. 2010), an increasing number of investigations have since been based on the GLOBE dimensions (Terlutter et al. 2005; Diehl et al., 2008; Terlutter et al. 2010; Diehl et al. 2012; Diehl et al., 2015; Mueller et al. 2016; Mueller et al. 2015; Matthes et al. 2016; and Czarnecka et al. 2018). With very few exceptions, studies relating GLOBE to 
advertising and marketing have focused on the United States, Western Europe and, to a lesser extent, South America. The present investigation seeks to reduce this research gap and to extend GLOBE based research to an Asian country.

\section{The GLOBE Dimension of Humane Orientation in Japan and the U.S.}

Of the nine GLOBE dimensions, Humane Orientation (HO) is most closely related to the concept of CSR. One explanation for the variation in consumer responses to CSR may be differences in their level of HO. Societies scoring high on HO "place importance on others (i.e. family, friends, community and strangers); believe that people are motivated by the need for belonging and affiliation; give high priority to values of altruism, kindness and generosity; and expect people to promote patronage norms and paternalistic relationships. Societies scoring low on this dimension believe that self-interest is important; that power and material possessions motivate people; that people are expected to solve problems on their own; and formal welfare institutions replace paternalistic norms and patronage relationships" (House et al. 2010, p. 122). At the corporate level, altruism, caring and generosity are closely associated with efforts by advertisers to highlight their socially responsible activities.

GLOBE explicitly differentiates between societal practices (which mainly reflect the current status and how issues are handled in a society, and therefore, the cultural practices) and societal values (the individuals' or society's sense of what ought to be as distinct from what is) (House et al. 2004). Given that values and practices in a society may be inconsistent and sometimes even contradictory, it is a major strength that GLOBE clearly distinguished between both levels of cultures. Cross-cultural research has emphasized the importance of distinguishing between the influence of culture on an individual level versus on a societal level (Schwartz 1994; Triandis, 1995). Because individuals are socialized in a particular culture, it is quite likely they adopt those values and practices that are shared among members of that society (Markus and Kitayama, 1991). With regard to societal and individual HO, culture-level data and individual-level data on $\mathrm{HO}$ can be expected to have similar but not necessarily identical patterns. For all 62 cultures investigated, House (2004, p. 573) reports that on a societal level the average score for HO practices was a middle-of-the-scale 4.09. The average for $\mathrm{HO}$ values was a much higher 5.42, indicating that in all 62 countries, $\mathrm{HO}$ is considered a desirable cultural dimension. In terms of HO practices, Japan - part of the Confucian Asian cluster, scores 4.30, while the U.S. - part of the Anglo cluster, scores 4.17. However, regarding HO values, the U.S. ranks somewhat higher at 5.53, compared to Japan at 5.41.

Diehl et al. (2015) developed a model (see Figure 1) of cross-cultural consumer responses to humane-oriented corporate social responsibility appeals in advertising, which was tested using structural equation modelling with data from six countries. Based on survey data from 924 subjects, the model received support in all six countries, suggesting that $\mathrm{HO}$ is a favorable cultural dimension for advertising purposes, even in countries in which HO is less highly valued. This model will be used to explore the role of HO in responses to advertisements containing CSR messages among consumers in Japan and the U.S. It postulates that the higher the perceived degree of HO in an advertisement, the more positive is the evaluation of the ad, and the more likely subjects are to perceive the advertiser as being socially responsible. These two variables positively influence attitudes towards the product and consequently, behavioral intentions. A moderating influence of country on the relationship between perception of $\mathrm{HO}$ in the ad and the evaluation of that ad and on the relationship between perception of $\mathrm{HO}$ in the ad and perceived degree of social responsibility of the advertiser is assumed (see Figure 1).

While Japan and the U.S. rank relatively similarly with regards to HO scores, the tradition of CSR has been very

different in the two countries, and the afore mentioned international industry CSR polls have suggested that though 


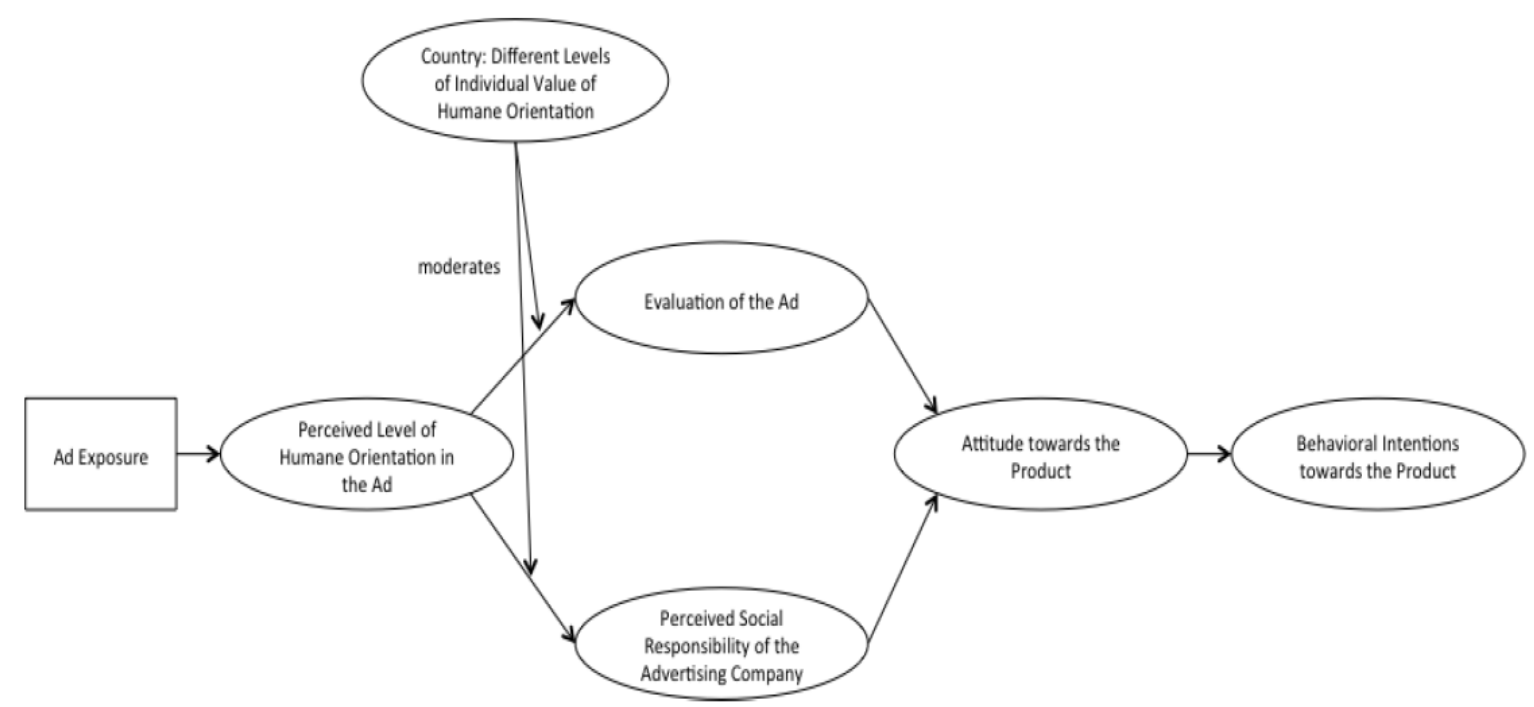

Fig. 1 Model of Consumer Responses to Humane-Oriented Advertising Appeals (Diehl et al., 2015)

Japanese have high expectations of their government and corporations in terms of making social and environmental changes, they are less likely to see a personal role for themselves. As a result, it may well be that humane-oriented advertising appeals will be less effective in Japan than in the U.S. Thus, while we assume that the model of crosscultural consumer responses to humane-oriented appeals in advertising by Diehl et al. (2015) will run in Japan as well, the paths related to $\mathrm{HO}$ are anticipated to be weaker in the Asian market. Based on this, we hypothesize:

H1 : The influence of perceived level of $\mathrm{HO}$ in the ad on perceived social responsibility of the advertising company (H1a) and on evaluation of the ad (H1b) is weaker in Japan than in the U.S.

H2 : The influence of perceived social responsibility of the advertising company on the attitude toward the product is weaker in Japan than in the U.S.

\section{Study Design and Methods}

\section{Stimulus material and pre-tests}

The model of cross-cultural consumer responses to humane-oriented appeals in advertising by Diehl et al. (2015) was tested in the Asian market using structural equation modelling, comparing the data previously collected in the U.S. with data collected in Japan for this study. A non-student survey was conducted in Tokyo (metropolitan area). The research process was designed to be identical to the initial investigation. The original questionnaire was translated into Japanese by bilingual speakers and then back-translated by different bilingual speakers to ensure consistency and accuracy of meaning. Because there are significant differences between English and Japanese in terms of sentence structure, it is quite important to conduct a pre-test when translated questions are used. To verify the reliability and validity of items, the questionnaire was pretested with 76 undergraduate students. Based on observations of the subjects and a review of the test results, the researchers refined the formatting and wording of the questions.

Mall intercept sampling is uncommon in Japan and conducting field surveys in commercial areas is generally restricted. Thus, sampling was instead conducted at private events, such as meetings and seminars. This was combined with snowball sampling. To ensure quality responses, subjects were offered gift card incentives (300 JPY: 
approximately, 3.24 USD) for their cooperation. In total Japanese 251 respondents participated in the survey (age range from 20 to 91, average age of 41.98; females 43\%, males 57\%). The sample is older in Japan than in the U.S. $(\mathrm{n}=199$, average age of $35.65, \mathrm{~F}=16.365, \mathrm{p}<.01$; females $53 \%$, males $47 \%)$. Japan has one of the oldest populations in the world (see e.g. He, Goodkind, and Kowal, 2016), and the Japanese sample reflects this.

\section{Procedure}

As in the previous Diehl et al. (2015) study, interviewers explained to subjects that the investigation dealt with consumer responses to advertising, but the true nature of the study with its focus on responses to CSR appeals was not disclosed. Subjects were informed that participation was completely voluntary and that all responses would remain anonymous. First subjects were asked some general questions about the product category (watches) as well as questions about their individual cultural values. Then subjects were shown the stimulus ad. The advertised product was a wristwatch employing a fictitious brand name ("Schwartz"), and featured a cause-related appeal. The primary visual in the stimulus ad portrayed a young woman engaging with small children in a playground setting. The children appear to be from a developing country. The headline read "We take responsibility." The body copy read: "Social responsibility is important to us at Schwartz. And for that reason, we support children in Kindergarten and grade school in developing countries with the sale of each of our watches." The CRM message was thus both visually and verbally woven into the ad. A shot of the watch was also included. Given that the average viewing time of a 1-page ad is typically about 2-5 seconds (e.g., Armstrong 2010), subjects were exposed to the stimulus ad for about 5 seconds. After exposure, respondents evaluated the ad, the product, and the advertiser, and were asked about their behavioral intentions. Several socio-demographic questions completed the questionnaire. As the majority of respondents completed the questionnaire independently, interviewer influence was minimized.

\section{Measurement of the Variables}

Table.1 reports the measurement of the variables with the items used.

Perceived Level of Humane Orientation in the Ad was measured via five questions. The questions were derived from descriptions of HO provided by House et al. (2010) and Kabasakal and Bodur (2004). The five questions were factor analyzed using confirmatory factor analysis (CFA). CFA results demonstrated a good model fit. Local fit measures (indicator reliability, factor reliability and average variance extracted) as suggested by Baumgartner and Homburg (1996) were acceptable as well. The scale was also tested for measurement invariance between countries following the procedure of Steenkamp and Baumgartner (1998) and the results indicate that partial measurement invariance across countries was supported. Cronbach Alpha values of perceived humane orientation in the ad were: U.S.: .915, Japan: .895. Evaluation of the Ad was assessed with four items, adapted from MacKenzie and Lutz (1989). Cronbach's $\alpha$ values were U.S.: .914, Japan: .901. Again, CFA demonstrated a good model fit. Partial measurement invariance across countries was supported. Perceived social responsibility of the advertising company was assessed with one item adapted from Nan and Heo (2007), which read: "I have the feeling that the Schwartz Corporation is socially responsible." (7-point scale, $7=$ high). Attitude towards the Product was assessed with four items, adapted from Mitchell and Olson (1981). Cronbach's $\alpha$ values were U.S.: .920, Japan: .888. CFA indicated a good model fit and partial measurement invariance across countries was supported. Behavioral Intentions were measured with three items adapted from Putrevu and Lord (1994). Cronbach's $\alpha$ values were U.S.: .925, Japan: .909. CFA indicated a good model fit. Partial measurement invariance across countries was also supported. Individual Humane Orientation 
Table 1 Variables and Items

\section{Perceived Level of Humane Orientation in the Ad}

The person responsible in the situation displayed in the ad seems to me $\cdots$

socially oriented

Sympathetic

Fair

Helpful

Caring

\section{Evaluation of the Ad}

Overall, I find the ad $\cdots$

The ad is interesting

The ad is likeable

The ad is pleasant

\section{Perceived Social Responsibility of the Advertising Company}

I have the feeling that the Schwartz Corporation is socially responsible

\section{Attitude towards the Product}

The product advertised in the ad is of high quality

The product is pleasant

The product is good

The product is attractive

\section{Behavioural Intentions}

Would you like to try the product

Could you imagine yourself buying this product

Could you imagine this product to be one of your most likely choices when you next buy a watch

\section{Individual Humane Orientation Values}

I should be more concerned about my fellow mankind

I should be more sensitive towards others

It should be more important to me to be friendly towards others

I should be more tolerant of the mistakes of others

I should be more generous towards others

I should be more fair towards others

I should take care of others more often

I should be more empathetic towards others

I should be more socially engaged 
Table 2 Path coefficients of the SEM

\begin{tabular}{|c|c|c|c|c|c|}
\hline \multicolumn{3}{|c|}{ Path } & \multicolumn{3}{|c|}{ Country } \\
\hline & & & U.S. & Japan & $\begin{array}{l}\text { CR of } \\
\text { difference }\end{array}$ \\
\hline Perceived level of $\mathrm{HO}$ in ad & $\rightarrow$ & $\begin{array}{l}\text { Perceived social responsibility } \\
\text { of advertising company }\end{array}$ & $.626^{* * *}$ & $.443^{* * *}$ & $2.799^{* * *}$ \\
\hline Perceived level of $\mathrm{HO}$ in ad & $\rightarrow$ & Evaluation of ad & $.656^{* * *}$ & $.348^{* * *}$ & $3.257^{* * *}$ \\
\hline Evaluation of ad & $\rightarrow$ & Attitude towards product & $.646^{* * *}$ & $.833^{* * *}$ & 1.166 \\
\hline $\begin{array}{l}\text { Perceived social responsibility } \\
\text { of advertising company }\end{array}$ & $\rightarrow$ & Attitude towards product & $.320 * * *$ & $.085^{*}$ & $3.279^{* * *}$ \\
\hline Attitude towards product & $\rightarrow$ & Behavioural intentions & $.625^{* * *}$ & $.777^{* * *}$ & 1.296 \\
\hline
\end{tabular}

$\chi^{2} / \mathrm{df}=2.99 ; \mathrm{CFI}=.933 ; \mathrm{TLI}=.926 ; \mathrm{RMSEA}=.067 \quad * * * \mathrm{p}<.01 ; \quad * * \mathrm{p}<.05 ; \quad * \mathrm{p}<.10$

Values were conceptualized based on GLOBE (House et al. 2004; Kabasakal \& Bodur 2004). Scales were adjusted and extended for the current investigation. Cronbach's Alpha values of individual humane orientation values were: U.S.: .960, Japan: .923. The nine questions were factor analyzed using CFA and a one-factor model for the HO measure was applied, yielding acceptable model fit.

\section{Results}

The data reveal that individual values of HO in Japan are lower than in the U.S.: Japan mean $=4.0752$; U.S. mean $=4.3019, \mathrm{~F}=2.882, \mathrm{p}=.09$ (hence only on the $10 \%$ level). This suggests that Japanese place less importance on $\mathrm{HO}$ as an individual value, a result which also reflects the findings for societal values from the GLOBE study, and for this reason the HO related paths are lower in Japan than in the U.S. The model was tested simultaneously in the two countries with a multi-group structural equation model with IBM SPSS AMOS Version 24. The model yielded global fit measures $(\mathrm{CFI}=.933 ; \mathrm{TLI}=.914 ; \mathrm{Chi} 2 / \mathrm{df}=2,99 ; \mathrm{RMSEA}=.067)$ that were deemed acceptable. In order to test whether the strengths of the relationships between the respective path coefficients in the outlined model vary significantly between the U.S. and Japan, structural invariance tests were conducted, using the critical ratio for difference statistic provided by AMOS. Table 1 reports the results of the analyses.

As reported in Table 2, a higher perceived level of $\mathrm{HO}$ in the ad leads to a stronger impression that the advertiser is socially responsible in both countries, U.S. (standardized path coefficient .626, p < .01) and Japan (.443, p < .01). Chi2-difference tests revealed that the relationship differs significantly between the two countries (Critical Ratio (CR) 2.799, $\mathrm{p}<.01$ ), thus confirming hypothesis H1a that the influence is weaker in Japan than in the U.S. Results also indicate that a higher perceived level of humane orientation in the ad has a positive impact on the evaluation of the ad (U.S. standardized path coefficient .656, p < .01; Japan .348, p <.01; CR of difference 3.257, p <.01). The significantly weaker relationship in Japan supports H1b. As expected, a more favorable evaluation of the ad (U.S. .646, p <.01; Japan .833, p <.01; CR of difference 1.166, n.s.) as well as a higher perceived level of social responsibility of the advertiser (U.S. .320, p <.01; Japan .085 ( $\mathrm{p}=.063$ ); CR of difference 3.279, p < .05) lead to a more favorable attitude towards the product. This latter path differed again significantly between the U.S. and Japan, lending support to H2. Finally, a more positive attitude towards the product also influenced behavioral intentions 
towards the product in a positive way (U.S. .625, p < .01; Japan .777, p < .01; CR of difference 1.296, n.s.).

\section{Discussion and Implications}

The study shows that the model of humane-oriented CSR appeals developed by Diehl et al. (2015) is also valid for Japan, one of the most important Asian markets. All paths were significant, however one path indicating that a higher perceived level of social responsibility on the part of the advertiser leads to a more favorable evaluation of the product, was only significant at the 10\%-level in Japan. To summarize, the higher the perceived degree of HO in the advertisement, the more positive were the evaluations of the ad, and the more likely subjects were to evaluate the message sender as being socially responsible. These two variables in turn positively influenced attitudes towards the product and consequently, purchase behavior. These results suggest that HO is a favorable cultural dimension for advertising purposes in Japan as well, even though the perception of HO has a lesser impact on advertising effectiveness than in the U.S. and other countries. As derived in the theoretical section, all three hypotheses were confirmed, which assumed lower influences of perceived humane orientation in the ad on advertising effectiveness. The influences of the perceived level of HO in the ad on the perceived social responsibility of the company and on the ad evaluation were weaker in Japan than in the U.S. and also the perceived social responsibility of the company yielded a weaker effect on the attitude toward the product. All other paths coefficients (which were not directly related to HO) did not differ significantly. Thus, despite the lower but still significant influence of HO on advertising effectiveness, results suggest that international advertisers may pursue a standardized campaign incorporating humane-oriented CSR appeals when appealing to consumers in both Japan and the U.S. The study contributes to the research gap regarding the effects of CSR advertising on consumers in Japan, also in addition to the call to analyse the GLOBE dimension in Asian countries.

\section{Limitations and Directions for Future Research}

A limitation of our investigation is that it employed just a single stimulus (one print ad). The investigation should be replicated employing different stimulus materials as well as different media (broadcast, on-line, etc.). Our stimulus ad featured a fictitious brand of wristwatch. It may be worthwhile to explore responses to existing brands employing HO appeals rather than limiting the investigation to a fictitious brand. Future investigators might also utilize a variety of products, ranging from low to high involvement, as well as services. Demographic variables warrant further examination. For example, Cheron, Kohlbacher and Kasuma (2012) found Japanese females showed more favorable attitudes toward CRM programs than did males. This study replicated the Diehl et al. (2015) model in only one Asian country. Researchers are encouraged to replicate the investigation in a broader range of Asian countries at varying stages of economic development - as it appears that many of the emerging markets are particularly committed to CSR, based on recent industry surveys. The focus of this investigation was HO. House et al. (2010) encouraged researchers to explore multiple dimensions of culture on advertising effectiveness. Finally, corporations can engage in a broad variety of CSR initiatives - CRM and humane-oriented CSR are but one form. The relative effectiveness of varying CSR tactics has received insufficient attention at the international level so far and thus presents an interesting research gap for future investigators.

Journal of Management and Training for Industries, Vol.5, No.3, 2018 


\section{References}

Armstrong, J. S., 2010. Persuasive Advertising: Evidence-based Principles,. New York, NY: Palgrave Macmillan.

Baumgartner, H. \& Homburg, C., 1996. Applications of Structural Equation Modelling in Marketing and Consumer Research: A Review, International Journal of Research in Marketing, 13(2), 139-161.

Bhattacharya, C. B. \& Sen, S., 2004. Doing Better at Doing Good: When, Why, and How Consumers Respond to Corporate Social Initiatives, California Management Review, 47(1), 9-24.

Cheron, E., Kohlbacher, F. and Kusuma, K., 2012. The Effects of Brand-cause Fit and Campaign Duration on Consumer Perceptions of Cause-related Marketing in Japan, Journal of Consumer Marketing, 29(5), 357-368.

Choi, S. and Aguilers, R. V., 2009. Corporate Social Responsibility Dynamics in South Korea and Japan: A Comparative Analysis, In C. A. Mallin (Ed.), Corporate Social Responsibility: A Case Study Approach, pp. 123-147, Cheltenham: Elgar.

Cone Communications, 2015. Ebiquity Global CSR Study, Retrieved January 20, 2018 from www.conecomm.com/ 2015-cone-communications-ebiquity-global-CSR-study-pdf/.

Czarnecka, B., 2018. Cultural Meaning, Advertising, and National Culture: A Four-country Study, Journal of Global Marketing, 31(1), 4-17.

DeMente, B., 2001. Japan Unmasked: The Kata Factor in Traditional Japanese Culture, Lambertville, NJ: Phoenix Books.

De Mooij, M. \& Hofstede, G., 2010. The Hofstede Model - Applications to Global Branding and Advertising Strategy and Research, International Journal of Advertising, 29(1), 85-110.

Diehl, S., Terlutter, R. \& Mueller, B., 2008. The Influence of Culture on Responses to The GLOBE Dimension of Performance Orientation in Advertising Messages - Results from The U.S., Germany, France, Spain and Thailand, Advances in Consumer Research, 35, 269-275.

Diehl, S., Terlutter, R. \& Mueller, B. 2012, June. Corporate Social Responsibility and Advertising: The Influence of Humane Orientation Appeals on International Consumer Attitudes toward the Ad and Product, Paper Presented at The International Conference on Research in Advertising (ICORIA), Stockholm.

Diehl, S., Terlutter, R. \& Mueller, B., 2015. Doing Good Matters to Consumers: The Effectiveness of Humaneoriented CSR Appeals in Cross-cultural Standardized Advertising Campaigns, International Journal of Advertising, 35(4), 730-757.

Edelman Goodpurpose Report, 2012. Executive Summary. Retrieved January 20, 2018 from https://slideshare. net/EdelmanInsights/global-deck-2012-edelman-goodpurpose-study.

Edelman Earned Brand Study, 2017. Retrieved January 20, 2018 from https://slideshare.net/EdelmanInsights/ 2017-edelman-earned-brand.

Ettinger, A., Terlutter, R., Diehl, S., \& B. Mueller, B., 2017. Integrated CSR Advertising: With a Special Focus on The Intercultural Perspective, In S. Diehl, M. Karmasin, Mueller, R, Terlutter, \& F. Weder (Eds.), Handbook of integrated CSR communication (pp. 251-272). Switzerland: Springer International Publishing.

Farooq, M.; Farooq, O. \& Jasimuddin, S. M., 2014. Employees Response to Corporate Social Responsibility: Exploring the Role of Employees' Collectivistic Orientation, European Management Journal, 32(6), 916-927.

Ford, J. B., Mueller, B. \& Taylor, C. R., 2011. The Tension between Strategy and Execution: Challenges for International Advertising Research, Journal of Advertising Research, 51(1), 27-41. 
Fukukawa, K. \& Moon, J., 2004. A Japanese Model of Corporate Social Responsibility? A Study of Website Reporting. The Journal of Corporate Citizenship, 16, 45-59.

Fukukawa, K. \& Teramoto, Y., 2009. Understanding Japanese CSR: The Reflections of Managers in the Field of Global Operations, Journal of Business Ethics, 85, 133-146.

Hall, E. T., 1976. Beyond Culture. Garden City, NY: Doubleday.

He, W., Goodkind, D. \& Kowal, P., 2016. An Aging World: 2015: International Population Reports.

Hofstede, G., 1980. Culture's Consequences: International Differences in Work-related values. Beverly Hills, CA: Sage.

Hofstede, G., 2001. Culture's Consequences: Comparing Values, Behaviors, Institutions, and Organizations Across Nations, 2nd ed. Thousand Oaks, CA: Sage.

House, R. J., Hanges, P. J., Javidan, M., Dorfman, P. W. \& Gupta, V., 2004. Culture, Leadership, and Organizations, Thousand Oaks, CA: Sage.

House, R. J., Quigley, N. R., \& Sully De Luque, M., 2010. Insights from Project GLOBE: Extending Global Advertising Research through a Contemporary Framework, International Journal of Advertising, 29(1), 111-139.

IB Times, 2011. Global Consumers Voice Demand for Greater Corporate Responsibility, Retrieved February 6, 2011 from WWw.ibtimes.com/art/services/print?php?articleid=225722.

Inglehart. World Values survey. Retrieved January 20, 2018 from http://www.worldvaluessurvey.org.

Kabasakal, H. \& Bodur, M., 2004. Humane Orientation in Societies, Organizations and Leader Attributes, In R.J. House, P. J. Hanges, M. Javidan, P. W. Dorfman and V. Gupta (Eds.), Culture, Leadership, and Organizations: The GLOBE Study of 62 Societies (pp. 564-601). Thousand Oaks, CA: Sage.

Kluckholn, F. R. \& Strodtbeck, F. L., 1961. Variations in Value Orientations, New York, NY: HarperCollins.

MacKenzie, S. B., \& Lutz, R. J., 1989. An Empirical Examination of the Structural Antecedents of Attitude toward the Ad in an Advertising Pretesting Context, Journal of Marketing, 53(2), 48-65.

Madden, D. \& Moon, J., 2004. Corporate Social Responsibility Education in Europe, Journal of Business Ethics, 54, 195-216.

Markus, H. R. \& Kitayama, S., 1991. Culture and the Self: Implications for Cognition, Emotion, and Motivation, Psychological Review, 38(2), 224-253.

Matthes, J., Prieler, M. and Adam, K., 2016. Gender Role Portrayals in Television Advertising across the Globe, Sex Roles, 75, 314-327.

Mitchell, A. A. \& Olson, J. C., 1981. Are Product Attribute Beliefs the Only Mediator of Advertising Effects on Brand Attitude? Journal of Marketing Research, 18(3), 318-332.

Mueller, B. \& Taylor, C. R., 2013. Convergence in Global Markets: The Great Standardization vs. Localization Debate is (Finally) Put to Rest, In S. Diehl \& M. Karmasin, (Eds.), Media and Convergence Management. Germany: Springer Publishing House.

Mueller, B., Terlutter, R. \& Diehl, S., 2015, June. The Torment of Gender Equality in Germany: Should Advertisers Care? Paper Presented at the International Conference on Research in Advertising (ICORIA), London.

Mueller, B., Diehl, S. \& Terlutter, R., 2016. The Effects of Gender Egalitarian Appeals in Advertisements on American Consumers, In P. Verlegh, H. Voorveld \& M. Eisend (Eds.), Advances in Advertising Research, Vol. VI (pp. 147-161). Wiesbaden, Germany: Springer, Gabler Publishers.

Mueller, K., Hattrup, K. \& Lin-Hi, N., 2012. The Effects of Corporate Social Responsibility on Employees' Affective Commitment: A Cross-cultural Investigation, Journal of Applied Psychology, 97(6), 1186-2000.

Journal of Management and Training for Industries, Vol.5, No.3, 2018 
Nan, X. \& Heo, K., 2007. Consumer Responses to Corporate Social Responsibility (CSR) Initiatives: Examining the Role of Brand-cause Fit in Cause-related Marketing, Journal of Advertising, 36(2), 63-74.

Nielsen 2014, June. Doing Well by Doing Good Report, Retrieved January 20, 2018 from www.nielsen.com/us/en/ insights/reports/2014/doing-well-by-doing-good.html.

Okazaki, S. \& Mueller, B., 2007. Cross-cultural Advertising Research: Where We Have Been and Where We Need to Go, International Marketing Review, 24(5), 499-518.

Pomering, A. \& Dolnicar, S., 2009. Assessing the Prerequisite of Successful CSR Implementation: Are Consumers Aware of CSR Initiatives? Journal of Business Ethics, 85, 285-301.

Putrevu, S. \& Lord, K. R., 1994. Comparative and Noncomparative Advertising: Attitudinal Effects under Cognitive and Affective Involvement Conditions, Journal of Advertising, 23(2), 77-91.

Schwartz, S. H., 1992. Universals in the Content and Structure of Values: Theoretical Advances and Empirical Tests in 20 countries, Advances in Experimental Psychology, 25, 1-65.

Schwartz, S. H., 1994. Are There Universals in the Content and Structure of Values? Journal of Social Sciences, 50, $19-45$.

Stanislawski, S. Sonobe, Y. \& Ohira, S., 2014. Japanese Consumers' Responses to CSR Messages on Product Packaging, Japan Forum of Business and Society: CSR and Corporate Governance, 161-183.

Steenkamp, J. B. E. M. \& Baumgartner, H., 1998. Assessing Measurement Invariance in Cross-national Consumer Research, Journal of Consumer Research, 25(1), 78-90.

Taylor, C. R., 2014. Corporate Social Responsibility and Advertising: Does It Extend to Taking Stances on Social Issues? International Journal of Advertising, 33(1), 11-15.

Taylor, C. R., 2018. Red Alert: On the Need for More Research on Corporate Social Responsibility Appeals in Advertising, International journal of Advertising, 37(3), 337-339.

Terlutter, R. Diehl., S. \& Mueller, B., 2005. The Influence of Culture on Responses to Assertiveness in Advertising Messages, In Advertising and Communication - Proceedings of the 4th International Conference on Research in Advertising (ICORIA), Saarbruecken, Germany, 183-192.

Terlutter, R., Diehl, S. \& Mueller, B., 2010. The Cultural Dimension of Assertiveness in Cross-cultural Advertising, International Journal of Advertising, 29(3), 369-399.

Triandis, H. C., 1995. Individualism and Collectivism, Boulder, Colorado: Westview.

Varadarajan, R. \& Menon, A., 1988. Cause-related Marketing: A Co-alignment of Marketing Strategy and Corporate Philanthropy, Journal of Marketing, 52(3), 58-74.

Wang, A. \& Anderson, R. B., 2011. A Multi-staged Model of Consumer Responses to CSR Communications, Journal of Consumer Citizenship, Spring, 51-68.

Witt, M. A. \& Stahl, G., 2016. Foundations of Responsible Leadership: Asian versus Western Executive Responsibility Orientations toward Key Stakeholders, Journal of Business Ethics, 136, 623-638.

Witt, M. A. \& Redding, G., 2012. The Spirits of Corporate Social Responsibility: Senior Executive Perceptions of the Role of the Firm in Society in Germany, Hong Kong, Japan, South Korea and the USA, Socio-Economic Review, 10(1), 109-134.

World Economic Forum, 2017. The World's 10 Biggest Economies in 2017. 9 March. Retrieved February 12, 2018 from https://www.weforum.org/agenda/2017/03/world's-biggest-economies-in-2017/.

Yoon, Y., Zeynep, G. C. \& Schwarz, N., 2006. The Effect of Corporate Social Responsibility (CSR) Activities on Companies with Bad Reputations, Journal of Consumer Psychology, 16(4), 377-390. 